\title{
Palm oil-based biodiesel synthesis by radiation-induced kenaf catalyst packed in a continuous flow system
}

\begin{abstract}
An efficient bio-based heterogeneous catalyst for biodiesel production was successfully fabricated by radiation-induced graft polymerization of 4-vinylbenzylchloride (VBC) followed by quaternary amination of trimethylamine (TMA) and ion-exchange with aqueous sodium hydroxide onto kenaf bast fiber using electron beam irradiation at a dose of $150 \mathrm{kGy}$. The produced catalyst was characterized by FESEM-EDX, CHNS, ATR-FTIR, TGA and XRD analyses. In this study, the continuous catalytic transesterification of triolein/ethanol in a bench-scale packed bed reactor (PBR) was designed and tested. The reaction process was focused at room temperature, different residence times from $1 \mathrm{~min}$ to $4 \mathrm{~min}$ and a molar ratio of triolein/ethanol (1:50). Besides, study on the transesterification of palm oil with ethanol under optimized conditions for maximum conversion of triolein to ethyl oleate (residence time of $3 \mathrm{~min}$, LHSV $=8 \mathrm{~h}-1$, short chain $150 \mathrm{kGy}$ catalyst) with temperature fixed at room temperature $\left(\sim 25^{\circ} \mathrm{C}\right)$ has been carried out. The extracted ethyl oleate was analyzed by HPLC and ATR-FTIR. The results found that the continuous flow system has a great potential for producing ethyl ester to be used as biodiesel and it is possible to generate $100 \%$ biodiesel with high purity from palm oil using radiation-induced kenaf catalyst.
\end{abstract}

Keyword: Bio-based heterogeneous catalyst; Kenaf fiber; Biodiesel; Radiation-induced graft polymerization; Fatty acid ethyl ester; Continuous flow system 